\title{
Error Correction in ESL: Learners' Preferences
}

James A. Oladejo

This paper reports the findings of two studies which attempt to identify the preferences and expectations of intermediate and advanced ESL learners regarding error correction. These are compared with some popular opinions of linguists and ESL teachers which have influenced error correction in the language classroom in recent time. Certain important differences are observed between learners' preferences and expectations on the one hand, and the opinions and practice of linguists/teachers on the other. The paper concludes that, if the error correction is to be effective, classroom practice cannot afford to be based rigidly on any standardized practice derived from the opinions of linguists and teachers alone, but it must be flexible enough to incorporate the preferences and needs of the language learner.

\section{INTRODUCTION}

Two of the major concerns of language teaching in the 1950s, and for a substantial part of the 1960 s, were error prevention and error correction. The audio-lingual approach which dominated the foreign/second language classroom at the time dictated that errors detected in the performance of the language learner be corrected comprehensively and immediately, so that they would not become part of his or her habit system. The correction of errors was to be the exclusive preserve of teachers, who were expected to show no tolerance of errors. As Brooks $(1960$, p. 58) put it, "like sin, error is to be avoided and its influence overcome, but its presence is to be expected".

In the late 1960s, following developments in interlanguage studies and the emergence of new thinking in second language acquisition studies (e.g. Corder, 1967; Selinker, 1972), new opinions emerged about the interpretation of learner errors, and support for the audio-lingual approach declined. Emphasis thenceforth shifted to fluency rather than accuracy in foreign language teaching; and soon afterwards, the revolution of communicative language teaching methodology began in many foreign language classrooms. Instead of insisting on error-free performance, teaching efforts began to focus on how to get the learner to communicate in the target language. In the words of Chastain (1971, p. 249), "more important than error 
free speech is the creation of an atmosphere in which the students want to talk."

The trend today in many ESL/EFL classrooms is that, although language learners' errors are no longer viewed negatively, and although the emphasis is now on getting the learner to communicate in the target language, as Wieczorek (1991, p. 498) rightly observes, there is still some orientation toward error correction as the main source of feedback to students. (See also Chaudron, 1988, p. 132). Thus, while many language teachers are willing to regard errors as a necessary part of learning, only a few are actually ready to ignore learners' errors totally. Even proponents of a task-based approach to language teaching in which attention is focused on meaning, rather than on form, have suggested some form of incidental error correction (Prabhu, 1989, p. 278). It is fair to surmise therefore that, despite the change in attitudes toward errors, and despite the revolution brought about by communicative approaches to language teaching, error correction and the ESL/EFL classroom are inseparably married.

Despite the partnership between error correction and the ESL/EFL classroom, research evidence has suggested that error correction may not be effective in getting the learner to perform correctly in the target language. Hendrickson (1978) has found some evidence that supplying correct lexical and grammatical forms has no statistically significant effect on students' writing proficiency. Indeed, over-correction of errors, especially at the early stage of learning, may be unproductive, if not also confusing and misleading to the learner (Chaudron, 1988, p. 135; Fanselow, 1977, p. 586). It is doubtful, therefore, if regular error correction is necessarily the remedy for ensuring correct performance in the target language. For, although the information made available through error correction may be expected to serve as feedback which enables the learner to confirm, disconfirm, and where necessary modify the hypothetical, transitional rules of his interlanguage, whether this objective is actually achieved will depend on a number of factors. For instance, the learner must not only be willing to see the target language form but he or she must also be ready to modify the hypothesis which originally generated the incorrect output (Chaudron, 1987, p. 20).

If error correction is to be effective as a major source of feedback to the learner, and as a means of generating correct target language performance, then teachers must be willing not only to change their attitudes toward errors, but they must also be ready to modify their old habits with regard to the practice of error correction in the 
language classroom. Evidence from research must be carefully examined and allowed to influence how errors are corrected. Given that any language teaching is an attempt to intervene in the process of language learning in order to quicken that process, the question that applied linguists and, indeed, language teachers must address should be how best can this intervention be carried out for the full benefit of the learner? More specifically on error correction, the question that must be carefully examined is how can error correction be done so that the learner's potential for learning the target language is not inhibited, but enhanced?

In a comprehensive review of research on error correction, Hendrickson (1978) attempts to provide answers to five relevant questions:

(a) Should learner error be corrected?

(b) If so, when should learner errors be corrected?

(c) Which learner errors should be corrected?

(d) How should learner errors be corrected?

(e) Who should correct learner errors?

But as Hendrickson himself points out, most answers provided to these questions by teachers and linguists were speculative and non-empirical. Without detailing the views he collates (see Burt \& Kiparsky, 1972; Gobert, 1974; Valdman, 1975; Fanselow, 1977; and Chaudron, 1987 for details), we must now recognize that, to date, no agreement exists on any of the questions raised above. Most of the opinions on strategies for error correction, though theoretically sound, are based on the views of language teachers and linguists. The opinions of learners, their preferences for error correction, and their views about different error correction procedures are almost totally neglected. Even where research has been conducted to identify learners' attitudes and preferences, it has been suggested that what the teacher eventually does with learners' errors need not depend on the outcome of the findings of such research (Chaudron, 1987 , p. 22). Yet, one would readily admit that it is important for learners to feel that their perceived needs are being catered to, if they are to develop a positive attitude toward what they are learning. It follows that, if serious considerations are not given to the learners' needs, there will be some impediments to learning. Conversely, how quickly and effectively the goal of learning is reached will depend largely on the matching of opinions and expectations of teachers and learners. 


\section{PURPOSE}

The purpose of this paper is to present the other side of the coin, the often neglected views and attitudes of learners to errors and error correction in language learning, and to compare them with some widely accepted opinions of EFL/ESL teachers. In seeking to identify the degree of parity of opinions and expectations of teachers and linguists on the one hand and those of the learners on the other, I shall focus on the issues raised by Hendrickson:

(a) Should learner errors in English be corrected?

(b) Which learner errors should be corrected?

(c) When should learner errors be corrected?

(d) Who should correct which type of errors made by learners?

(e) How should learner errors be corrected?

I shall also address two additional questions which are important for our understanding of how learner errors should be treated. The first is, are there attitudinal differences between learners studying different major subjects, such differences as might influence their needs for error correction? It is widely accepted that the learners' perceptions of what they are learning influences their attitudes, and consequently, how well they learn. The question being asked therefore is: do all learners have similar attitudes toward error correction? Secondly, it is relevant to ask if the learners' level of acquisition has anything to do with their attitude toward error correction. In other words, do learners at different levels of acquisition differ in their preferences in terms of the aspects of the target language they would want error correction to be focused on? Research findings have suggested that learners want to be corrected more often than teachers think (Cathcart \& Olsen, 1976; Hendrickson, 1978; and Chun, Day, Chenoweth \& Luppescu 1982). But we do not know specifically whether the preferences of learners vary according to their level of competence in the language. It is assumed that with increasing levels of competence, the preferences and wants of the learners will change, thus reflecting the differences in the areas of difficulty at different acquisition levels.

\section{RESEARCH DESIGN}

Two sets of data are examined in order to provide some answers to the questions raised above. The first set is that collected by my student, L. K. Lim (1990), who investigated the attitudes, opinions, 
and expectations of secondary school pupils in Singapore to errors and error correction in English language. The second set which seeks to investigate similar questions with university undergraduates comes from a study conducted by the author. The two sets of data allow a comparision between the opinions of learners at different levels of language learning.

Lim asked 147 secondary school pupils to complete a set of questions designed to investigate three specific issues: (a) pupils' preferences for error correction, (b) their perceptions of the nature of errors, and (c) the attitudes of learners at different exposure levels to errors and error correction. Using a similar but not exactly identical questionnaire, I asked 500 undergraduates of the National University of Singapore from five faculties (Architecture and Building, Arts and Social Sciences, Business Administration, Engineering, and Science), who had registered for proficiency courses in English, to answer certain questions designed to elicit information on their opinions and preferences on error correction. Since certain issues Lim was interested in for her research are not of interest to the present study, modifications were made to her questionnaire in order to make it suitable for this study. (A sample of the questionnaire for the present study is included as Appendix A). Learners were asked to freely express their opinions by completing the questionnaire individually in class. It was important to ensure that they were not allowed to consult with one another or take the questionnaire out of class in order to prevent cross-fertilization of opinions. Preliminary testing of the questionnaire showed some ambiguities in certain questions, and these were rectified before administration to the actual subjects. The questionnaire was administered only after the subjects seemed to have clearly understood the content.

It should be stressed here that neither Lim's questionnaire nor the details of her results will be presented in this paper for lack of space. The results will, however, be used for the purpose of comparison with my own data in order to provide answers to some of the questions of this research. 


\section{RESULTS}

Tables 1 - 5 summarize the findings of the study.

TABLE 1

Responses On Whether Learner Errors Should Be Corrected

\begin{tabular}{|c|c|c|c|c|}
\hline & $\begin{array}{l}\text { Strongly } \\
\text { Agreed }\end{array}$ & Agreed & Disagreed & $\begin{array}{l}\text { Strongly } \\
\text { Disagreed }\end{array}$ \\
\hline $\begin{array}{l}\text { i. It is necessary to correct } \\
\text { learners' errors in English so } \\
\text { that they can use the language } \\
\text { more accurately and fluently. }\end{array}$ & $\begin{array}{c}182 \\
(36.4 \%)\end{array}$ & $\begin{array}{c}270 \\
(54 \%)\end{array}$ & $\begin{array}{c}36 \\
(7.2 \%)\end{array}$ & $\begin{array}{c}12 \\
(2.4 \%)\end{array}$ \\
\hline $\begin{array}{l}\text { ii. Teachers should overlook } \\
\text { grammatical errors and focus } \\
\text { only on errors that inhibit com- } \\
\text { munication so that learners are } \\
\text { not frustrated. }\end{array}$ & $\begin{array}{c}34 \\
(6.8 \%)\end{array}$ & $\begin{array}{c}38 \\
(7.6 \%)\end{array}$ & $\begin{array}{c}282 \\
(56.4 \%)\end{array}$ & $\begin{array}{c}146 \\
(29.2 \%)\end{array}$ \\
\hline $\begin{array}{l}\text { iii. Errors should be corrected } \\
\text { only if the majority of learners } \\
\text { seem to have difficulties with } \\
\text { the features concerned. }\end{array}$ & $\begin{array}{c}68 \\
(13.6 \%)\end{array}$ & $\begin{array}{c}20 \\
(4 \%)\end{array}$ & $\begin{array}{c}112 \\
(22.4 \%)\end{array}$ & $\begin{array}{c}300 \\
(60 \%)\end{array}$ \\
\hline $\begin{array}{l}\text { iv. Constant error correction } \\
\text { can cause frustration and dis- } \\
\text { courage the learner from using } \\
\text { the language. }\end{array}$ & $\begin{array}{c}16 \\
(3.2 \%)\end{array}$ & $\begin{array}{r}74 \\
(14.8 \%)\end{array}$ & $\begin{array}{c}96 \\
(19.2)\end{array}$ & $\begin{array}{r}314 \\
(62.8 \%)\end{array}$ \\
\hline
\end{tabular}

TABLE 2

Responses On Which Learner Errors Should Be Corrected

\begin{tabular}{lrrrr}
\hline \hline & $\begin{array}{c}\text { High } \\
\text { Attention }\end{array}$ & $\begin{array}{c}\text { Some } \\
\text { Attention }\end{array}$ & $\begin{array}{c}\text { Little } \\
\text { Attention }\end{array}$ & $\begin{array}{r}\text { No } \\
\text { Attention }\end{array}$ \\
\hline Orpects & $400(80 \%)$ & $76(15.2 \%)$ & $16(3.2 \%)$ & $8(1.6 \%)$ \\
Granization & $350(70 \%)$ & $132(26.4 \%)$ & $11(2.2 \%)$ & $7(1.4 \%)$ \\
Pronunciation & $104(20.8 \%)$ & $294(58.8 \%)$ & $90(18 \%)$ & $12(2.4 \%)$ \\
Vocabulary & $252(50.4 \%)$ & $222(44.4 \%)$ & $24(4.8 \%)$ & $2(0.4 \%)$ \\
Spelling & $94(18.8 \%)$ & $8(1.6 \%)$ & $126(25.2 \%)$ & $272(54.4 \%)$ \\
Punctuation & $48(9.6 \%)$ & $26(5.2 \%)$ & $208(41.6 \%)$ & $218(43.6 \%)$ \\
\hline
\end{tabular}


TABLE 3

\section{Responses On When Errors Should Be Corrected}

\begin{tabular}{lrrrr}
\hline \hline Aspects & Always & Occasionally & \multicolumn{1}{c}{ Rarely } & Never \\
\hline Organization & $360(72 \%)$ & $117(23.4 \%)$ & $14(2.8 \%)$ & $8(1.6 \%)$ \\
Grammar & $260(52 \%)$ & $214(42.8 \%)$ & $22(4.4 \%)$ & $4(0.8 \%)$ \\
Pronunciation & $192(38.4 \%)$ & $262(52.4 \%)$ & $40(8 \%)$ & $6(1.2 \%)$ \\
Vocabulary & $252(50.4 \%)$ & $230(46 \%)$ & $12(2.4 \%)$ & $6(1.2 \%)$ \\
Spelling & $162(32.4 \%)$ & $290(58 \%)$ & $38(7.6 \%)$ & $10(2 \%)$ \\
Punctuation & $82(16.4 \%)$ & $130(26 \%)$ & $268(53.6 \%)$ & $20(4 \%)$ \\
\hline
\end{tabular}

TABLE 4

Responses On Who Should Correct Which Errors

\begin{tabular}{lrrr}
\hline \hline Aspects & \multicolumn{1}{c}{ Teacher } & \multicolumn{1}{c}{ Self } & \multicolumn{1}{c}{ Classmates } \\
\hline Organization & $376(75.2 \%)$ & $90(18 \%)$ & $34(5.6 \%)$ \\
Grammar & $368(73.6 \%)$ & $104(20.8 \%)$ & $28(5.6 \%)$ \\
Pronunciation & $288(57.6 \%)$ & $116(23.2 \%)$ & $96(19.2 \%)$ \\
Vocabulary & $370(74 \%)$ & $90(18 \%)$ & $40(8 \%)$ \\
Spelling & $136(27.2 \%)$ & $292(58.4 \%)$ & $72(14.4 \%)$ \\
Punctuation & $184(36.8 \%)$ & $250(50 \%)$ & $66(13.2 \%)$ \\
\hline
\end{tabular}

TABLE 5

Responses On How Errors Should Be Corrected

\begin{tabular}{lrccc}
\hline \hline $\begin{array}{l}\text { Methods of } \\
\text { Error Correction }\end{array}$ & $\begin{array}{c}\text { Most } \\
\text { Preferred }\end{array}$ & $\begin{array}{c}\text { Some } \\
\text { Preference }\end{array}$ & $\begin{array}{c}\text { Hardly } \\
\text { Preferred }\end{array}$ & $\begin{array}{c}\text { Not } \\
\text { Wanted }\end{array}$ \\
\hline $\begin{array}{l}\text { i. Show error, } \\
\text { no answer }\end{array}$ & $28(5.6 \%)$ & $144(28.8 \%)$ & $188(37.6 \%)$ & $140(28 \%)$ \\
$\begin{array}{l}\text { ii. Error + answer } \\
\text { iii. Error + cues for }\end{array}$ & $210(42 \%)$ & $170(34 \%)$ & $96(19.2 \%)$ & $24(4.8 \%)$ \\
$\begin{array}{l}\text { self correction } \\
\begin{array}{l}\text { iv. Use errors for } \\
\text { class examples }\end{array}\end{array}$ & $272(54.4 \%)$ & $178(35.5 \%)$ & $32(6.4 \%)$ & $18(3.6 \%)$ \\
$\begin{array}{l}\text { v. No comments } \\
\text { at all }\end{array}$ & $176(35.2 \%)$ & $196(39.2 \%)$ & $110(22 \%)$ & $18(3.6 \%)$ \\
\hline
\end{tabular}




\section{DISCUSSION}

\subsection{Should Learner Errors In English Be Corrected?}

Responses to question (a) i (see Appendix A) show a general agreement by learners with the view that "it is necessary to correct their errors in English in order to enhance their fluency and accuracy in the language". (See Table 1 for details). Not only do the learners want their errors corrected, but they also prefer such correction to be comprehensive, rather than selective. The majority of the learners disagree, some strongly, with the view that grammatical errors should be overlooked in favour of errors that inhibit communication (Table 1, item ii). There is also a numerically strong disagreement with the suggestion that errors should be corrected only if the majority of learners seem to have difficulty with the features concerned. As item iii, Table 1 shows, more than $80 \%$ of the respondents disagree with the view. It is interesting also to note that the majority of the learners disagree with the view that "constant error correction could frustrate the learner and inhibit his willingness to perform in the language." Here again, more than $80 \%$ of the respondents disagree with the view (item iv). The findings reported here are similar to Lim's (p. 30ff.). She observed that well over $90 \%$ of the secondary school pupils investigated disagreed with the view that selective error correction should be practiced.

\subsection{Which Learner Errors Should Be Corrected?}

Although learners generally want their errors corrected, they also have preferences in terms of how much emphasis each error type should attract. The majority of the learners believe that errors relating to organization of ideas should receive the highest attention for correction.

Grammatical errors rank next in order of preference for correction, with more than $96 \%$ of the learners indicating that this error type deserved high attention, or some attention. Learners' preference for error correction shows that grammatical errors is followed closely by vocabulary errors, while pronunciation errors comes after it in order of priority. Receiving the least priority for correction are spelling and punctuation errors which the majority of the learners would like to be given little or no attention. (See Table 2 for details.) 
Lim's results of the opinions of learners on which error categories should receive more attention than others in terms of correction show a different pattern from the ones reported above. Although grammar and vocabulary errors were indicated by the majority of the learners as deserving high attention, errors of organization of ideas were not. The results show the following order of preference by the secondary pupils she investigated: Grammar, Vocabulary, Spelling, Pronunciation, Organization of Ideas, and Punctuation.

The fact that the two sets of learners differ in their views on how much emphasis should be given to each error type could be related to the different demands on the learners at different levels of exposure to the language. For at the relatively advanced (i.e. university) level, the demand on learners to compose and express ideas would be higher than at the intermediate (secondary) level.

\subsection{When Should Learner Errors Be Corrected?}

Learners' responses to the above question suggest that, although they want error correction to be comprehensive, certain error types are expected to require correction more frequently than the others. Three types of errors are identified by the majority of the learners as requiring correction always, namely, errors of organization of ideas, grammar, and vocabulary. (See Table 3 for details.) On the other hand, the majority of the respondents think that errors of pronunciation, spelling, and punctuation deserve correction only occasionally or even rarely.

There is a striking similarity between the opinions of the learners here and those investigated by Lim (p. 38ff.). The majority (65\%) of her subjects indicate that grammatical errors should be corrected always, while correcting vocabulary errors always attract $64 \%$ support. $57 \%$ of them also feel that errors of organization of ideas should be corrected always. As in the case of the university students, errors of pronunciation, spelling, and punctuation are felt to require correction only occasionally or rarely.

\subsection{Who Should Correct Learner Errors?}

Although Corder (1973) and Allwright (1975) suggest that the teacher should be primarily responsible for correcting learners' errors, it is now generally agreed that students also have significant roles to play, if error correction is to be effective. In this respect, it has been suggested that both self-correction and peer-correction 
should be encouraged to complement the teacher's role in error correction (Wingfield, 1975; Raven, 1973; Cohen, 1975; and Witbeck, 1976). The question, however, is not whether learners should be asked to participate in error correction, but which error types should they be asked to correct. Witbeck (p. 325) in an experiment of four peer correction methods observed that peer correction led to "greater concern for achieving accuracy in written expression in individual students and creates better atmosphere for teaching the correctional aspects of composition" (emphasis mine). The implication is that there may be certain aspects of language where peer correction or even self correction would not be as successful. Indeed, Witbeck (p. 324) was careful to note in the case of one of the methods he examined, "feedback and rewriting correction procedure," that "peer correction did not lead to noticeable improvement in all cases." As he pointed out, the main problem encountered was that students did not know what to look out for.

Both my data and those of L. K. Lim show that students have preferences as to who should be primarily responsible for correcting which type of errors. The majority of learners feel that errors of organization of ideas, vocabulary, grammar, and pronunciation would be best corrected by the teacher, while spelling and punctuation errors should be taken care of by learners themselves (see Table 4 for details). It is important to note also that the majority of my subjects feel that none of their errors should be corrected by their peers, although the same is not true of the learners studied by Lim. Her results show that the secondary school pupils are generally favorably disposed to peer correction. It seems, therefore, that the relatively advanced learners' attitude to peer-correction is not exactly the same as those of the secondary school pupils, and this method of error correction might not be as successful for the advanced learners as it might be in the case of the intermediate ones.

The feeling that errors of organization, vocabulary, pronunciation and grammar are best corrected by the teacher might have to do with the fact that these aspects of the language are more difficult for the learners than are punctuation and spelling. It is also possible that since both spelling and punctuation errors are in most cases local errors, learners consider them to be less important than the other error types in terms of their roles in communication. 


\subsection{How Should Learner Errors Be Corrected?}

Of the five error correction techniques suggested [see Appendix A, item (e)], the one most preferred by the learners in my study is that the teacher should provide relevant comments and cues which might enable them (the learners) to self-correct. Preferred next to that is the technique of showing the errors and providing the right answers. Learners' preferences for the other three methods are as follows in descending order: "Use of errors as class examples", "simply showing errors without providing a clue", and "no comments at all, just give grades". A huge majority (95\%) of the learners expressed little or no preference for this last method. (See Table 5 for details.) Although Lim examined only three of the above procedures in her study, her finding is very similar to the one reported above. $61 \%$ of the pupils most prefer the method of showing errors and providing clues for self-correction, while $41 \%$ prefer that they be provided with the correct answer in addition to being told what was wrong. Only $10 \%$ of the pupils preferred no comments at all on their works.

\subsection{Attitudinal Differences Between ESL Learners Studying Different Subjects}

A detailed analysis of my data does not reveal any significant differences in the attitudes of learners in different faculties towards error correction in English. The majority of the learners in each of the faculties examined agree with the views that error correction is desirable, and that correction should be comprehensive rather than selective. Although, given the possibility that accuracy in English language would be more important for students in the humanities than for those in the sciences, one would have expected some attitudinal differences on error correction between learners in science based faculties such as Engineering, Science, Architecture and Building, on the one hand and those in the Humanities on the other. The result of this study suggests that the learners have similar views on both the desirability and the scope of error correction.

\subsection{Attitudinal Variation According to Acquisition Level}

Here, we take a closer look at the similarities and differences between the results of this study and those of Lim in order to determine whether the attitudes of learners toward error correction 
in ESL differ according to their level of proficiency in the language. As we have seen in 5.1, the opinions of the university learners investigated here on the need for error correction are similar to those of the less advanced learners studied by Lim. Similarly, as the discussion in 5.3 shows the opinions of both sets of learners on when learner errors should be corrected are similar. In addition, the two sets of learners seem to agree in their views about how learner errors should be corrected (see 5.5).

However, as we have seen in 5.2 and 5.4 respectively, there are important differences between the opinions of the two categories of learners on which learner errors should be corrected, and who should correct which errors. The observed differences in their responses here might reflect either the demand for English language on the different sets of learners, or the focus of teaching activities at the different levels. For it is likely that the secondary school pupil is more concerned about grammar, and less with organization of ideas, which is more of a problem at higher level studies. It is also possible that while the focus of teaching at the tertiary level is more on composition and organization of ideas, that of the secondary school is probably more on grammar. As for the different attitudes toward peer correction as discussed in 5.4, such attitudinal differences may be explained in terms of age differences between the two sets of learners. This idea is taken up further in section 6 below.

\section{IMPLICATIONS}

We have noted in the discussion that the majority of learners believe that error correction is desirable in order to enhance both fluency and accuracy in English language. We have also seen that learners generally seem to disagree with the now current belief in applied linguistic circles about the need for selective error correction in order not to frustrate the learners (Burt, 1975; George, 1975). Similarly, learners generally disagree with the view that constant error correction could result into frustration (Burt \& Kiparsky, 1972). Rather, they seem to want to be corrected more often and more thoroughly than language teachers sometimes assume (Cathcart \& Olsen, 1972). Similarly, there is no agreement between teachers and learners regarding which error types should be considered more important than the others for the purpose of correction. The emerging picture is that errors which inhibit communication, and these necessarily include vocabulary, are considered to be important, but even surface grammatical errors which 
teachers might want to ignore are also important to learners. Learners also prefer certain methods of error correction to others (5.5). Finally, we have noticed some significant differences between learners at different levels of exposure to the language (5.7).

Two major issues are raised by these results. First, there appear to be significant differences between some widely held opinions and practices concerned with error correction in the ESL/EFL class on the one hand, and the opinions and expectations of ESL/EFL learners on the other. For example, it is popularly believed that peer correction is very helpful in the ESL classroom, and Cohen (1975) has suggested that this approach would help the learners recognize errors and enable them to focus more on grammatical rather than lexical errors (Burt \& Kiparsky, 1972; Valdman, 1975; and Corder, 1975 hold similar views). But the results of this study indicate that while this view may be true in a broad sense, it may not necessarily be successful in all situations. For as we have already noted, advanced ESL learners prefer both teacher and self correction to peer correction for almost all their errors, while the learners at the intermediate level are generally well disposed to peer correction. One possible explanation for the difference in the attitudes of the two sets of learners towards peer correction is that the advanced learners may have developed certain affective characteristics which tend to emphasize independent learning, while those at the lower levels are less influenced by such factors. Consequently, the advanced ESL learners may put up some defense mechanism which would make peer correction less successful. One must also admit the possibility that this kind of attitude toward peer correction at the advanced level may not be replicated in other ESL/EFL situations, where the culture may be more tolerant toward peer evaluation. It is well known that in the predominantly Chinese culture of Singapore peer correction is often seen negatively, as a sign of losing face. So, the finding reported here must be interpreted only in the context of the cultural background of the learners.

Another example of the differences between teachers' beliefs and learners' expectations might be relevant. It has been observed that the most popular error correction method used by teachers is to show the learners' errors and provide the correct answers (Fanselow, 1977). The results of the present study suggest that the method most preferred by language learners is that of providing cues or comments that would enable them to self correct, although the intermediate learners would also like to be told their errors and be provided with correction. For this category of learners, providing 
correct answers might in fact be a necessary step toward getting them to be confident and to communicate. Given these differences between what the teacher believes and the opinions of the learner, could it be that the teacher's assumptions are sometimes wrong, or is it a case of the learner not knowing what is good for him or her? More research is needed before any reliable answer can be found. In the meantime, one obvious implication of the findings reported here is that we must exercise caution on how we apply our intuition to classroom practices.

The second main issue raised by the study is that as far as error correction in the ESL classroom is concerned, certain important differences exist between the preferences and expectations of learners at different levels of exposure to the target language. Thus it is not only important to note the different expectations and preferences of language learners on error correction, but also the fact that these variables change with learners' level of exposure to the language.

Although I have found no significant differences in the general attitudes to error correction among ESL learners in different faculties, this result must be interpreted carefully. Given the fact that English is the lingua franca of Singapore, the variability that would have been found among learners in a different learning situation where, for instance, the language plays a less significant role, may actually have been concealed in the present study. After all, regardless of the Singaporean learners' main subject of study, they still need English for their day to day activities and for survival. In a different setting, where the learner needs English for strictly academic purposes, for example, there might be less demand for accuracy in English usage, and consequently, the learner's attitude to errors and correction might differ from what we have observed here.

\section{CONCLUSION}

Two general conclusions can be drawn from the findings of this study. First, since teachers' opinions and classroom practice regarding error correction do not always match the perceived needs and expectations of learners, such mismatch could contribute to lack of success in language learning. It follows that, if teachers are to intervene positively in language learning, we must begin to think how best we can meet our learners' needs. While not suggesting that practitioners should abandon their beliefs and practices regarding error correction, we should be willing to examine critically some 
of the things we believe in and practise, in the light of new evidence. Where necessary, such beliefs and practice should be modified to cater to the learners' expectations and needs.

Secondly, our approach to error correction in the language classroom cannot afford to be rigid. The fact that differences exist between the expectations and preferences of learners at different levels of exposure not only places a demand on the teacher to be vigilant in identifying these differences, but it also calls for flexibility on his or her part so as to cope with different demands. For example, it has been suggested that grammatical errors should be given less attention, especially in the performance of beginning learners, while communicative errors should be of more importance in order to ensure that such learners attain some level of confidence in communicating in the target language (Powell, 1973, 1975; Hanzeli, 1975). But given the finding that both grammatical and communicative errors are actually considered important by learners, can we afford to stick to the recommended practice in every situation? Whether or not we adopt a suggested approach should depend not on what we think but on the needs of our learners. A note of caution must, however, be sounded here on the possible application of the above conclusion and the recommendations based on it. As I have pointed out, the absence of certain attitudinal differences between learners in different disciplines may not imply that differences will never exist. In the same way, the observed differences between learners at different levels of proficiency may have been influenced by the cultural setting of the learners. It should be made clear, therefore, that the particular ESL/EFL situation one is dealing with should be carefully examined in order to come to a decision on how best to approach error correction. The best decisions on how to correct learners' errors effectively, which errors to correct, when to do so, and who should do it, can be made only with a thorough analysis of the needs and expectations of the learners, carefully considered against the ESL/EFL cultural background and the learners' level of exposure. The classroom teacher should then be willing to let the result of his or her analysis influence personal opinions and practice of error correction. What we need for a successful practice of error correction in the ESL classroom is not a standardized manual, but the ability to be sensitive to the exposure level of our students, their attitudes, opinions, expectations, and cultural background, and the willingness to incorporate them into classroom practice. 


\section{ACKNOWLEDGEMENTS}

I would like to thank Drs. N.S. Prabhu, B.K. Das, and Jean D'Souza and the anonymous reviewers of TESL Canada Journal for their insightful comments on the draft of this paper.

\section{THE AUTHOR}

James Oladejo was born in Nigeria where he had his initial education before obtaining a Ph.D. from the University of Reading, England. He taught for many years in Nigeria and Singapore before joining the Papua New Guinea University of Technology as a senior lecturer in English Language and Communications.

\section{REFERENCES}

Allwright, R. L. (1975). Problems in the study of the language teacher's treatment of learner error. In M. K. Burt \& H. C. Dulay (Eds.), New directions in second language learning, teaching and bilingual education (pp. 96-109). Washington, DC: TESOL.

Brooks, N. (1960). Language and language learning. (2nd Ed.). New York: Harcourt, Brace \& World Inc.

Burt, M. K. (1975). Error analysis in the adult EFL classroom. TESOL Quarterly, 53-63.

Burt, M. K. \& Kiparsky, C. (1972). The gooficon: A repair manual for English. Rowley, MA: Newbury House.

Cathcart R. L. \& Olsen, J. E. (1972). Teachers' and students' preferences for error correction of classroom conversation errors. In J. F. Fanselow \& R. H. Crymes (Eds.), On TESOL '76 (pp. 41-53). Washington, DC: TESOL.

Chastain, K. (1971). The development of modern language skills: Theory to practice. Philadelphia: Center for Curriculum Development, Inc.

Chaudron, C. (1987). The role of error correction in second language teaching. In B. K. Das (Ed.), Patterns of classroom interaction in Southeast Asia. Singapore: RELC.

Chaudron, C. (1988). Second language classrooms: Research on teaching and learning. Cambridge: Cambridge University Press.

Chun, A. E., Day, R. R., Chenoweth, N. A. \& Luppescu, S. (1982). Errors, interaction and correction: A study of native-nonnative conversations. TESOL Quarterly, 16, 537-547. 
Cohen, A. D. (1975). Error correction and the training of language teachers. Modern Language Journal, 59, 414-422.

Corder, S. P. (1967). The significance of learners' errors. IRAL 5(4).

Corder, S. P. (1973). Introducing applied linguistics. Harmondsworth, Great Britain: Penguin.

Corder, S. P. (1975). The language of second language learners: The broader issues. Modern Language Journal, 59, 409-413.

Fanselow, J. F. (1977). The treatment of error in oral work. Foreign Language Annals, 10, 583-593.

George, H. V. (1975). Common errors in language learning. Rowley, MA: Newbury House Publishers.

Gobert, F. (1974). Error analysis: What the teacher can do. A new perspective. Ottawa: Research Division, Public Service Commission of Canada.

Hanzeli, V. E. (1975). Learners' language: Implications of recent research for foreign language instruction. Modern Language Journal, 59, 426-432.

Hendrickson, J. M. (1978). Error correction in foreign language teaching: Recent theory, research and practice. Modern Language Journal, 62, 387-398.

Lim, L. K. (1990). Students' attitudes towards errors and error correction in language learning. An Academic Exercise submitted for the award of the degree of B.A., National University of Singapore.

Powell, P. B. (1973). An investigation of selected syntactical and morphological structures in the conversation of secondary students after two years' study of French. Unpublished Doctoral dissertation, The Ohio State University.

Powell, P. B. (1975). Error analysis in the classroom. ERIC clearinghouse for languages and linguistics. Arlington, VA: Center for Applied Linguistics.

Prabhu, N. S. (1989). Three models in second language pedagogy. Journal of English and Foreign Languages, 3, 1-13.

Raven, R. (1973). Language acquisition in a second language environment. In J. W. Oller \& J. C. Richards, (Eds.), Focus on the learner: Pragmatic perspective for the language teacher. New York: Newbury House.

Selinker, L. (1972). Interlanguage. IRAL 10(3).

Valdman, A. (1975). Learner system and error analysis. In A. J. Gilbert, (Ed.), Perspective: A new freedom (pp. 219-258). Skokie, IL: National Textbook Co. 
Wieczorek, J. A. (1991). Error evaluation, interlanguage analysis, and the preterit in the Spanish L2 classroom. The Canadian Modern Language Review, 47(3), 497-511.

Wingfield, R. J. (1975). Five ways of dealing with errors in written compositions. English Language Teaching Journal, 29, 311-313.

Witbeck, M. C. (1976). Peer correction procedures for intermediate and advanced ESL composition lessons. TESOL Quarterly, $10,321-326$.

\section{APPENDIX A}

(a) Indicate agreement or disagreement with each of the following claims (Suggested responses: Strongly Agree, Agree, Disagree, Strongly disagree):

i. It is necessary to correct learners' errors in English so that they can use the language more accurately and fluently.

ii. Teachers should overlook grammatical errors and focus only on errors relating to expression, so that learners are not frustrated.

iii. Errors should be corrected only if the majority of learners seem to have difficulty with the features concerned.

iv. Constant error correction can cause frustration and discourages the learner from using the language.

(b) What amount of attention would you suggest should be given to correcting your errors in each of the following aspects of the language: Grammar, Pronunciation, Organization of ideas, Vocabulary, Spelling, and Punctuation? (Available answers are: High attention, Some attention, Little attention, No attention.)

(c) Errors in each of the following areas of language should be corrected: Always, Occasionally, Rarely, Never. (Classify each error type under a heading).

Grammar, Pronunciation, Vocabulary, Organization of ideas, Spelling, and Punctuation. 
(d) Who do you think should be primarily responsible for correcting the following kinds of errors in students' work: Grammar, Pronunciation, Vocabulary, Organization, Spelling, and Punctuation errors? (Suggested answers are: Teacher, Student (self), Classmates (peers).

(e) Using the following descriptions, Most Preferred; Some Preference; Hardly Preferred; Not Preferred; indicate your preference for each of the following error correction techniques often used by ESL teachers.

i. Point out the wrong item(s) without providing the correct answer(s).

ii. Show the wrong item(s) and provide the answer(s).

iii. Show the wrong item(s) and give cues to the student to enable self correction.

iv. Just grade the work without indicating which errors are made. 